15 st/

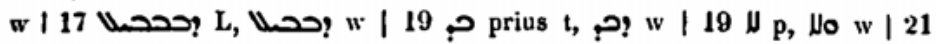

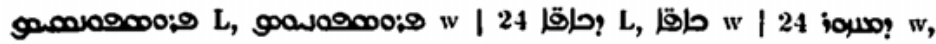

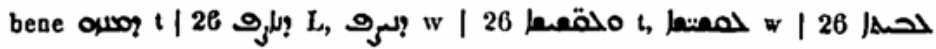

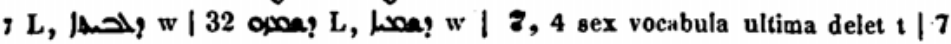

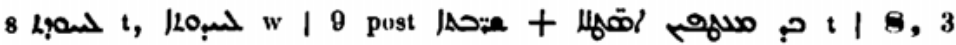

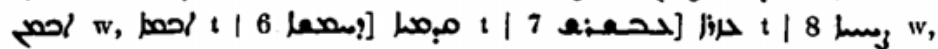

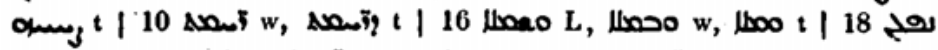

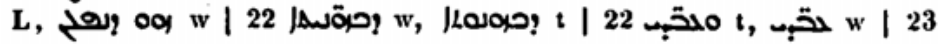

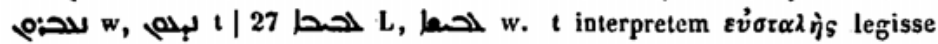

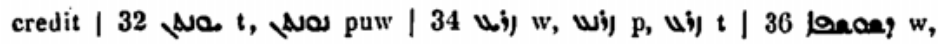

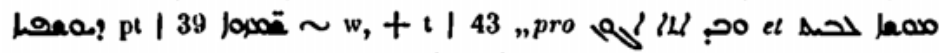

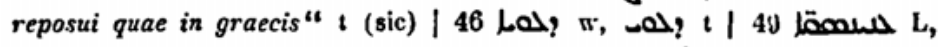

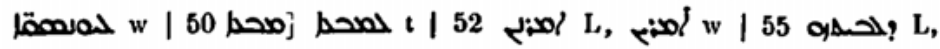

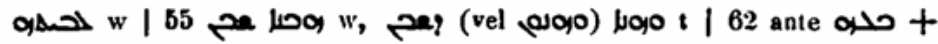

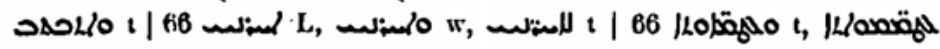

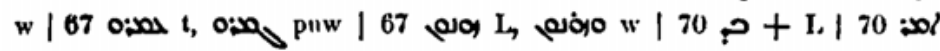

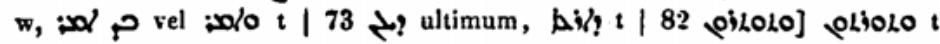

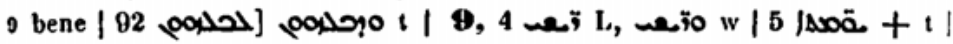
|

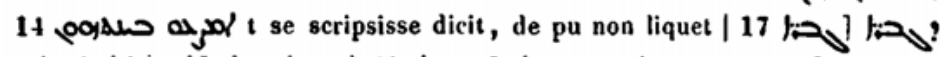

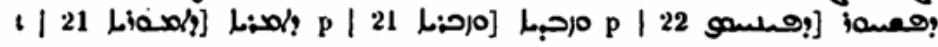
p | 27 | 37 e graeco corrigit t pro more | 38 | حمد

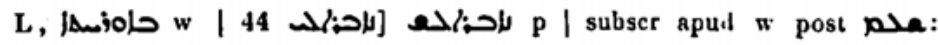

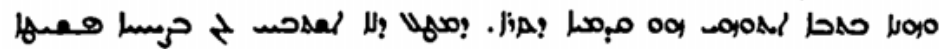

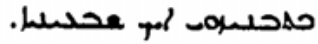

\title{
Maccabaeorum primụs
}

Tilulus apud w: مبمار

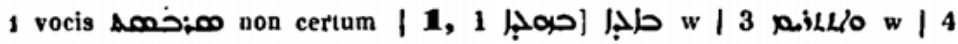

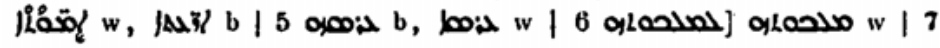
مأم paw. ceterum Antiuchum

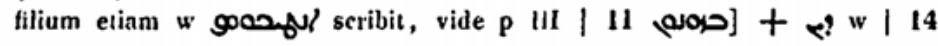

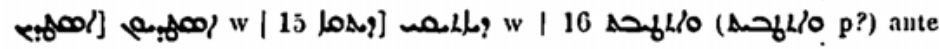

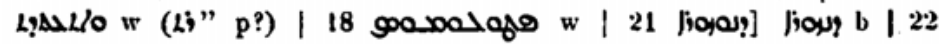

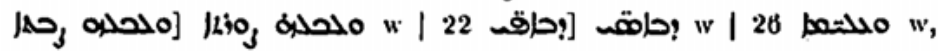

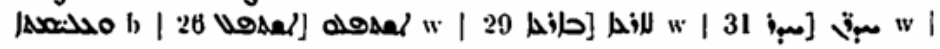




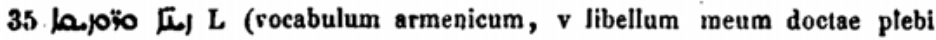
frustra invisum zur urgeschichte der Armenier p 36 (1002), reliq iur

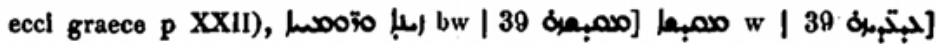

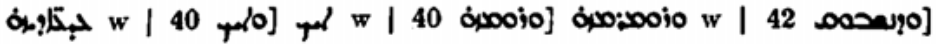

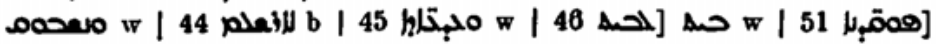

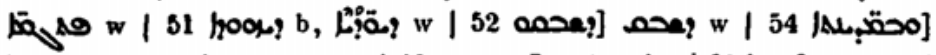

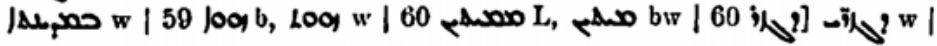

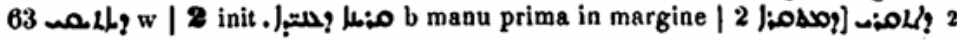

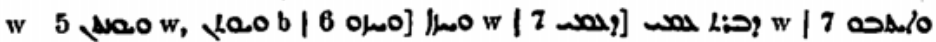

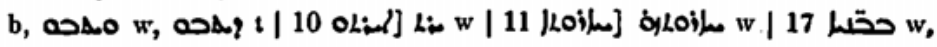

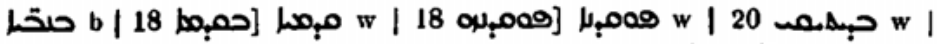

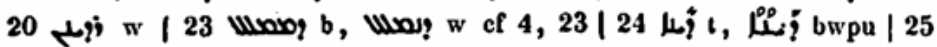

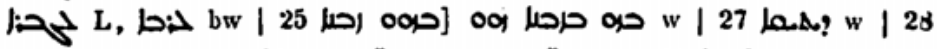

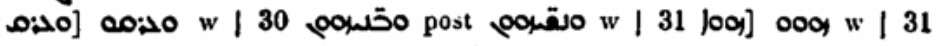

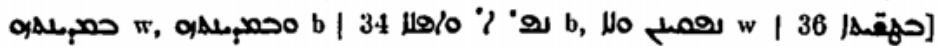

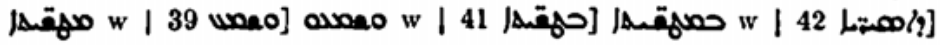

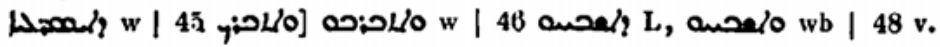

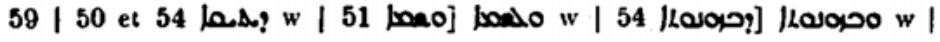

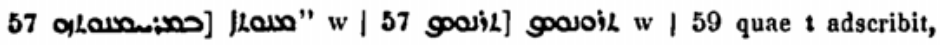

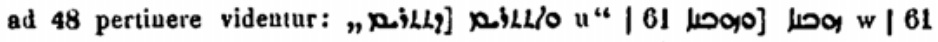

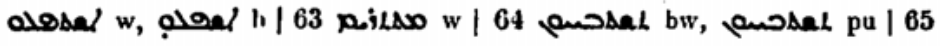

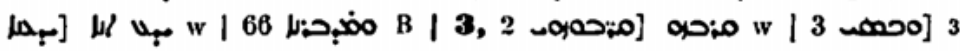

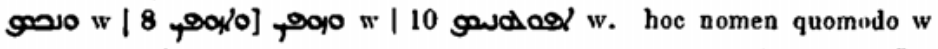
scriptum exhibeat operae pretium non est commemorare | 12 a a a

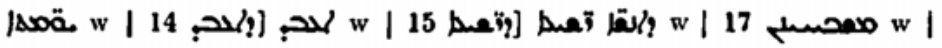

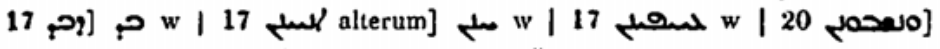

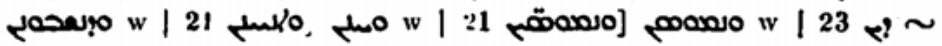

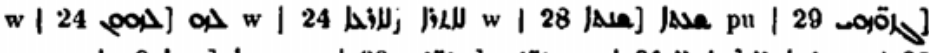

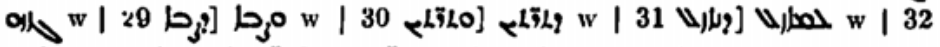

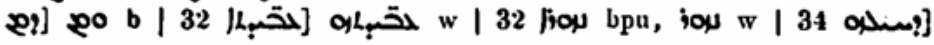

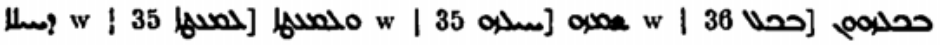

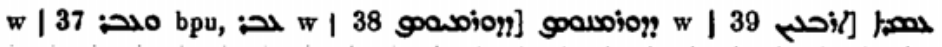

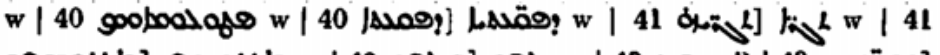

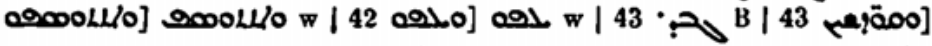

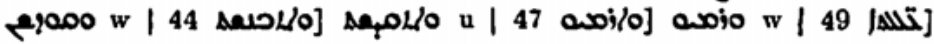

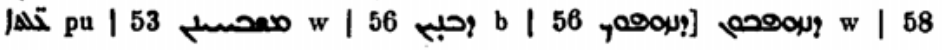

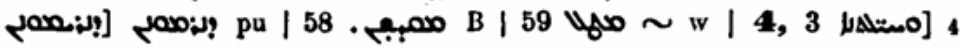

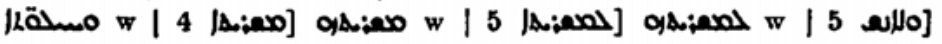

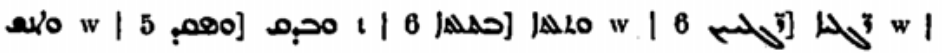




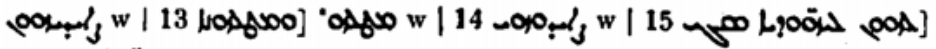

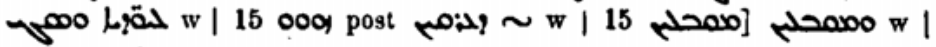

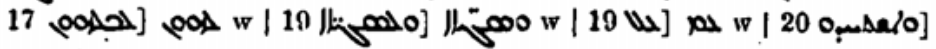

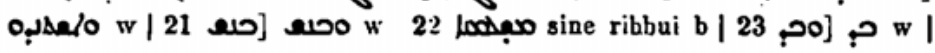

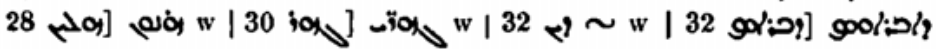

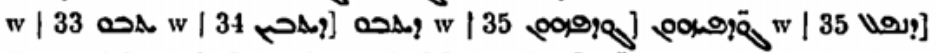

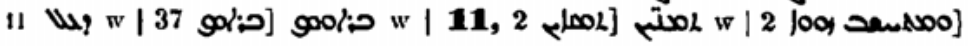

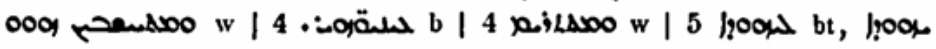

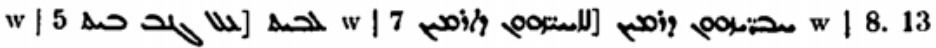

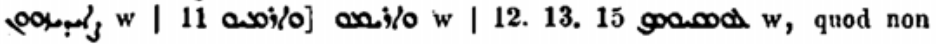
adnotabo amplius | 17 Yud in podero incertissimum in b | 17 /

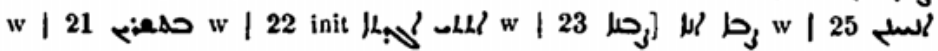

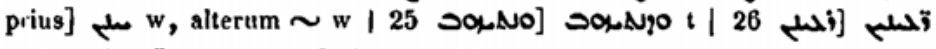

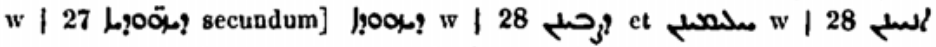

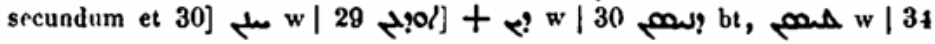
quatuor nomina literis graccis miniatis in marg b.

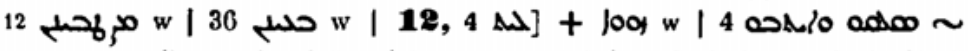

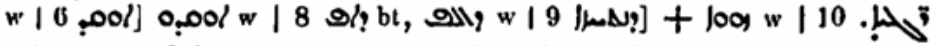

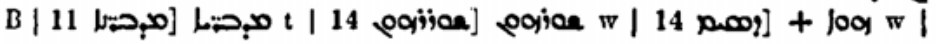

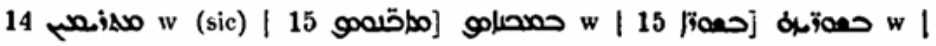

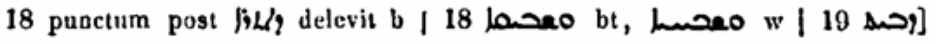

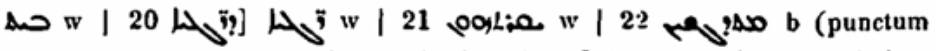

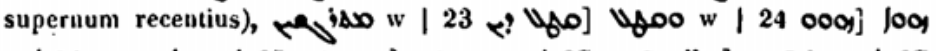

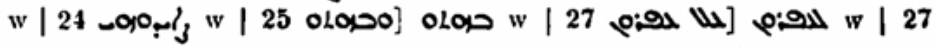

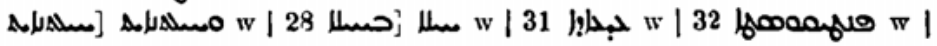

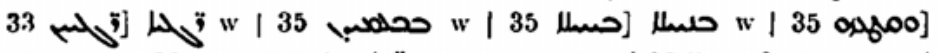

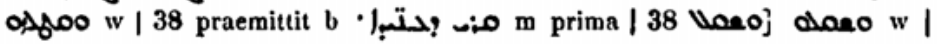

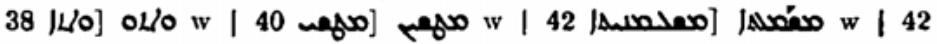

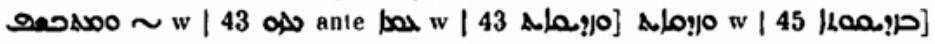

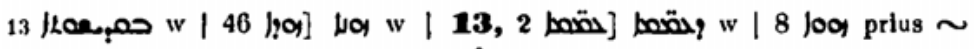

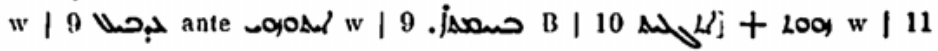

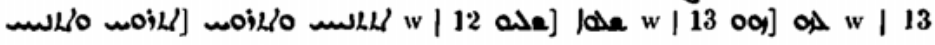

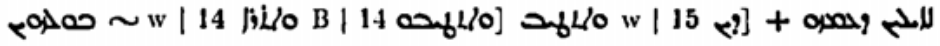

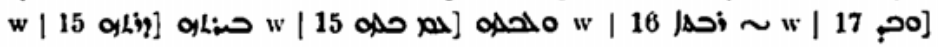

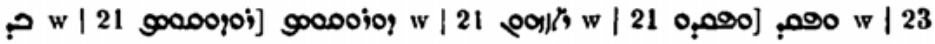

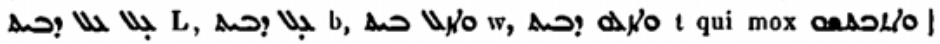

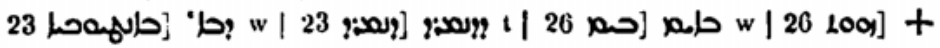

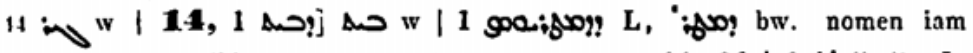

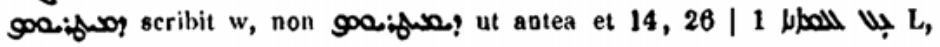




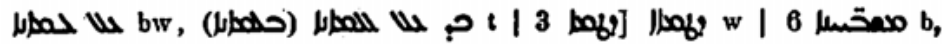
on cum vsu 7 con-

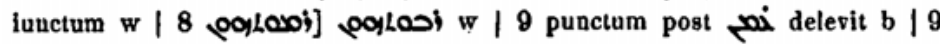

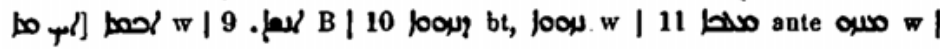

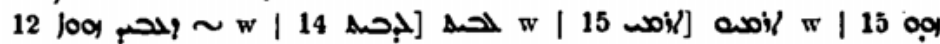

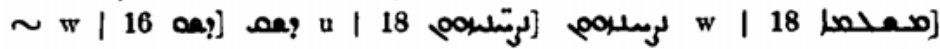

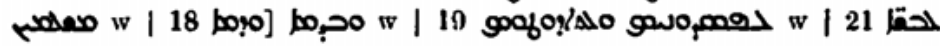

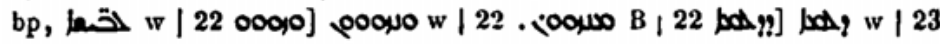

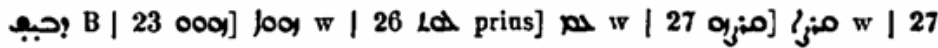

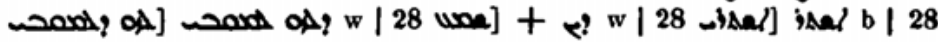

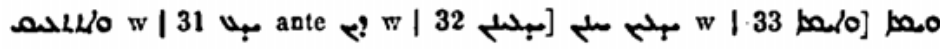

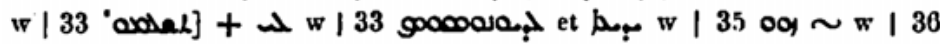

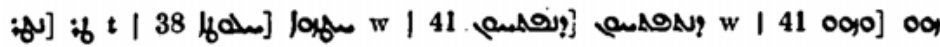

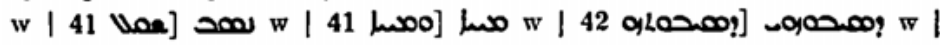

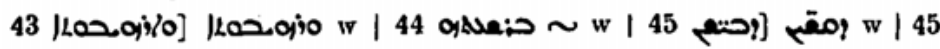

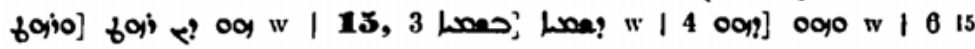

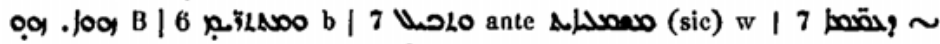

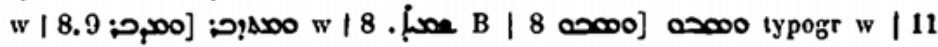

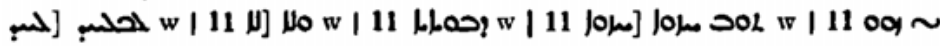

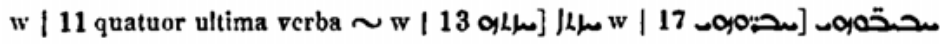

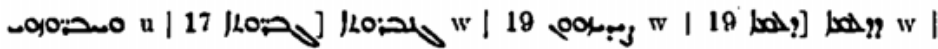

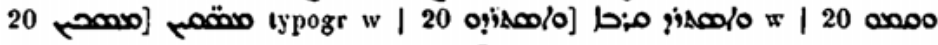

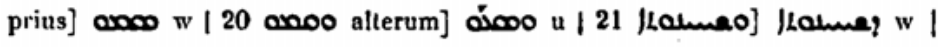

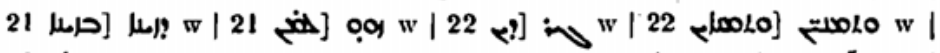

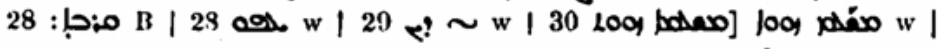

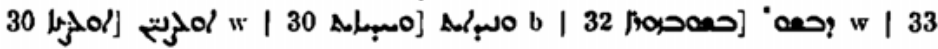
apoo] [achos w I 33 post lacna trium literarum in b | 34

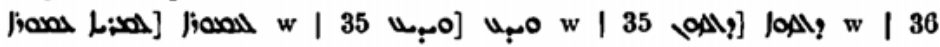

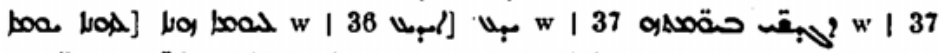

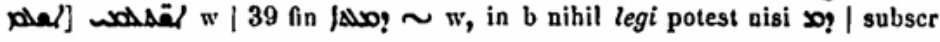

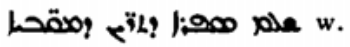

\section{Maccabaeorum tertius}

Titulus praem sol w | 1, 3 will L, مده; 1

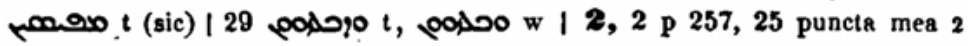

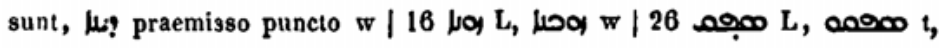

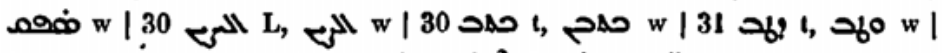

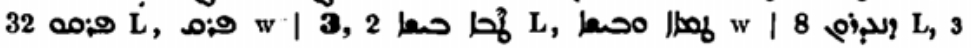

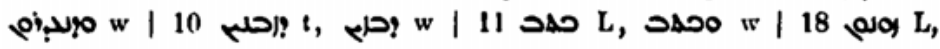

